\title{
MALDI Imaging and Profiling MS of Higher Mass Proteins from Tissue
}

\author{
Alexandra van Remoortere, ${ }^{\mathrm{a}}$ René J. M. van Zeijl, ${ }^{\mathrm{a}}$ Nico van den Oever, \\ Julien Franck, ${ }^{\mathrm{c}}$ Rémi Longuespée, ${ }^{\mathrm{c}}$ Maxence Wisztorski, ${ }^{\mathrm{c}}$ Michel Salzet, ${ }^{\mathrm{c}}$ \\ André M. Deelder, ${ }^{a}$ Isabelle Fournier, ${ }^{c}$ and Liam A. McDonnell ${ }^{\mathrm{a}}$ \\ a Biomolecular Mass Spectrometry Unit, Department of Parasitology, Leiden University Medical Center, \\ Leiden, The Netherlands \\ ${ }^{\mathrm{b}}$ Hogeschool Leiden, Leiden, The Netherlands \\ c Université de Lille1, CNRS-FRE 3249, MALDI Imaging Team, Laboratoire de Neuroimmunologie et \\ Neurochimie Evolutives, Villeneuve d'Ascq, France
}

MALDI imaging and profiling mass spectrometry of proteins typically leads to the detection of a large number of peptides and small proteins but is much less successful for larger proteins: most ion signals correspond to proteins of $\mathrm{m} / \mathrm{z}<25,000$. This is a severe limitation as many proteins, including cytokines, growth factors, enzymes, and receptors have molecular weights exceeding $25 \mathrm{kDa}$. The detector technology typically used for protein imaging, a microchannel plate, is not well suited to the detection of high $\mathrm{m} / \mathrm{z}$ ions and is prone to detector saturation when analyzing complex mixtures. Here we report increased sensitivity for higher mass proteins by using the CovalX high mass HM1 detector (Zurich, Switzerland), which has been specifically designed for the detection of high mass ions and which is much less prone to detector saturation. The results demonstrate that a range of different sample preparation strategies enable higher mass proteins to be analyzed if the detector technology maintains high detection efficiency throughout the mass range. The detector enables proteins up to $70 \mathrm{kDa}$ to be imaged, and proteins up to $110 \mathrm{kDa}$ to be detected, directly from tissue, and indicates new directions by which the mass range amenable to MALDI imaging MS and MALDI profiling MS may be extended. (J Am Soc Mass Spectrom 2010, 21, 1922-1929) () 2010 American Society for Mass Spectrometry

S ince its inception $\sim 10 \mathrm{y}$ ago, MALDI imaging mass spectrometry (imaging MS) has developed into a powerful and versatile tool for biomedical research [1, 2]. It is now routinely used for analyzing peptides and small proteins up to $25 \mathrm{kDa}$ [3-6], administered drugs and their metabolites [7], and recently major improvements have been reported for lipids [8]. Despite this success, proteins exceeding $25 \mathrm{kDa}$ are not routinely detected. Proteins larger than $25 \mathrm{kDa}$ include many proteins with important biological activities, such as most cytokines, growth factors, enzymes, receptors, proproteins, and neuropeptide precursors. Increasing the mass range of proteins amenable to MALDI imaging MS might enable these biologically crucial proteins to be included in current applications, e.g., biomarker discovery.

The most common technique currently used to access larger proteins in MALDI imaging MS analyses is based on proteolytic digestion of the tissue's proteins followed by MALDI imaging MS of their tryptic peptides. Note on-tissue digestion has the additional advantage that it can be applied to formalin fixed tissues

Address reprint requests to Dr. L. McDonnell, Biomolecular Mass Spectrometry Unit, Department of Parasitology, Leiden University Medical Center, Albinusdreef 2, 2333ZA Leiden, The Netherlands. E-mail: 1.a. mcdonnell@lumc.nl as proteolytic peptides can be generated that are not bound within the cross-linked protein matrix. For example, Djidja et al. used on-tissue digestion to determine that the $78 \mathrm{kDa}$ protein GRP78 may be a new candidate protein biomarker of pancreatic adenocarcinoma [9]. In principal, this 'bottom-up' strategy could enable proteins of any mass to be detected. In practice the large increase in complexity associated with proteolysing the entire tissue's protein content will cause many tryptic peptides to have identical nominal mass [1], thus undermining the identification of potential biomarkers. Furthermore, bottom-up MALDI imaging MS discards all information regarding protein isoforms unless the appropriate tryptic peptides are explicitly included in the analysis. Recently it was shown that post-mortem protein degradation of GRP78, the protein identified as a candidate biomarker in the above bottomup strategy, is isoform-dependent [10], and it is difficult to control protein degradation in human tissue samples. Direct MALDI imaging MS of proteins, if performed with sufficient mass resolution, would have the advantage that many isoforms can be identified on the basis of the resulting difference in mass.

MALDI imaging MS of higher mass proteins has been conspicuous by its rarity. Three recent articles have reported sample preparation methods that help 
increase the mass range of proteins amenable to the technique. The first method uses extensive water washing steps to deplete abundant soluble proteins, followed by application of a matrix solution containing a high percentage of organic solvent. This preparation allowed the detection of a $28 \mathrm{kDa}$ integral crystalline lens membrane protein [11], but would be difficult to apply as a general strategy as its success is based solely on extensive on-tissue protein purification of membrane proteins (which remain anchored to the insoluble membrane during the repeated water washes). The second method uses Triton X-100 and xylene to aid the detection of proteins ranging from $m / z 25,000$ to 50,000 [12]. The images were very noisy, indicating insufficient intensity, but provided several lines of reasoning for the lack of sensitivity for higher mass proteins. The use of organic solvents or Triton X-100 suggests higher mass proteins may not be detected because they are not efficiently solubilized by the matrix solution and consequently are not extracted from the tissue. Franck et al. recently extended these sample preparation strategies and reported how the solvents 1,1,1,3,3,3-hexafluoro-2propanol (HFIP) and 2,2,2-trifluoroethanol (TFE) could also be used for MALDI MS analysis of tissues [13]. Unfortunately the very low viscosity and harsh chemical abrasiveness of HFIP and TFE make them difficult to apply with the automated sample preparation stations commonly used for MALDI imaging MS.

All of the above sample preparation strategies report empirical methods by which the signals of higher mass proteins could be increased but have not addressed an inherent weakness in the mass spectrometry: MALDI predominantly generates singly charged protein ions so a high mass protein ion will be detected at high $m / z$. The technology typically used for protein MALDI imaging or profiling MS, a time-of-flight (TOF) mass spectrometer equipped with a micro-channel plate (MCP) detector, is not well suited to the detection of high $\mathrm{m} / \mathrm{z}$ ions [14]. The initial impact of an ion onto the detector releases some electrons, which are then amplified through the MCP to generate the signal. The MCP detection process is known to favor lower $m / z$ ions because the ion to electron conversion efficiency is nonlinearly dependent on velocity, exhibiting a 'threshold' velocity below which no signal is obtained, then increasing rapidly with increasing velocity before reaching a plateau in which detector response in insensitive to increasing velocity [15]. In TOF analyzers ion velocity is inversely proportional to the square root of the $m / z$ ratio. Ions of high $m / z$ may not be detected within the optimum detection-efficiency plateau and thus generate less detector signal. Furthermore, MCP detectors have a finite amplification potential within any single time-of-flight scan $[16,17]$. Lower mass ions, detected first, can saturate the detector, leading to even lower detection efficiencies for higher mass ions [16, 17].

The lower sensitivity of TOF mass analyzers using MCP detectors for higher mass ions has been known for some time. Chen et al. have demonstrated that the lower ion-to-electron conversion of higher mass ions, detector saturation, and $m / z$-dependent ion transmission (to the detector) are sufficient to explain the entirety of the observed decrease in signal intensity with increasing mass (without invoking any chemical bias) [14]. This study was primarily concerned with oligonucleotide detection but also demonstrated that protein analysis provided equivalent results. Furthermore, this investigation of the instrumental effects that are responsible for the decreased sensitivity of higher mass ions was performed using a simple mixture of just seven oligonucleotides. Even with this relatively simply system, saturation of the MCP detector could reduce the intensities of the heavier oligonucleotides by 80\% [17]. In MALDI applications in proteomics, such as peptide fingerprinting and LC-MALDI, high mass insensitivity is rarely a problem since complex mixtures of proteins with masses above 20,000 are rarely analyzed. The tissue sections analyzed by MALDI imaging and profiling MS can result in a significant background, which is more intense in the low mass region but continues throughout the entire mass range $[18,19]$. When detecting a wide mass range, this background will exacerbate MCP detector saturation and further decrease the detection efficiency for higher mass protein ions. Low mass ions are routinely deflected (or the detector bias switched) to avoid intense low mass ions, such as matrix and lipid ions, from saturating the detector [17]. Nevertheless in MALDI imaging and profiling MS the significant background and lower mass peptide and protein ions represent a high ion load that will reduce detection efficiency for higher mass ions.

Hillenkamp and workers have investigated highmass detection of MALDI generated ions using a single stage dynode [20] and used this technology to analyze large molecular ions [21, 22]. Commercial detectors explicitly designed for the detection of higher mass proteins and protein complexes have been designed by Comet and CovalX. The Comet Macromizer is based on a superconducting tunnel junction (STJ) cryodetector. The STJ detector can detect very low kinetic energies and is able to perform single ion detection on the basis of their kinetic energy [23]. In a MALDI-TOF instrument, the kinetic energy of an ion is determined by the accelerating potential and charge state of the ion, consequently an STJ detector is able to detect all ions with equal efficiency (no mass dependence) [20]. A particular advantage of STJ detectors is that multiply charged ions can be distinguished on the basis of their higher kinetic energy. The higher detection efficiency and higher capacity of the STJ detector has been exploited for the analysis of complex protein mixtures: it was demonstrated that the STJ detector could detect multiple higher mass proteins that were not detected using an MCP [24]. Unfortunately the Comet Macromizer is no longer commercially available.

The high mass detectors from CovalX, HM1 and HM2, use an ion conversion detector to increase the detection sensitivity of higher mass ions: incident ions 
first collide with a conversion dynode array to create smaller secondary ions, which are then reaccelerated into a secondary electron multiplier as higher velocity ions that are detected with higher sensitivity [25]. In addition to more sensitive detection of higher mass protein ions, these high mass detectors possess a much larger charge capacity and thus are not as prone to detector saturation as the typical MCP detector [25]. Here we demonstrate that a commercial detection system optimized for high mass ions and which is much less prone to detector saturation, CovalX's HM1 detector, significantly improves the sensitivity of MALDI imaging and profiling MS for higher mass proteins. Its combination with recently reported sample preparation procedures for accessing higher mass proteins enables these very large ions to be detected from tissue with higher sensitivity, and includes the demonstration of MALDI imaging MS of proteins exceeding $50 \mathrm{kDa}$ and the first MALDI profiling MS of proteins exceeding $100 \mathrm{kDa}$.

\section{Experimental}

\section{Materials}

Sinapinic acid (SA), 1,1,1,3,3,3-hexafluoro-2-propanol (HFIP), trifluoroacetic acid (TFA), ethanol (EtOH), acetone, acetonitrile $(\mathrm{AcN})$, chloroform, Tween 20, sodium dodecyl sulfate (SDS), Triton X-100, and hydrogen peroxide were purchased from Sigma-Aldrich (Zwijndrecht, The Netherlands) and used without further purification. Peroxidase-blocking reagent containing $3 \%$ hydrogen peroxide was purchased from Dako (Heverlee, Belgium).

\section{Samples}

Adult male Wistar rats weighing 250-350 g and adult male wild type mice weighing 30-50 g (animal use accreditation by the French ministry of the agriculture no. 04,860$)$ maintained under standard care were used. Animals were sacrificed by decapitation and immediately dissected to remove the brain, which was then flash frozen in liquid nitrogen and stored at $-80^{\circ} \mathrm{C}$.

\section{Tissue Preparation}

Thin $12 \mu \mathrm{m}$ thick tissue sections were cut using a cryomicrotome and thaw mounted onto conductive glass slides (Delta Technologies, Stillwater, MN, USA). The tissue sections were then freeze dried for $1 \mathrm{~h}$ followed by different washing steps to remove salts and abundant lipids. Each tissue section was first immersed in a bath of cold acetone for $30 \mathrm{~s}$ followed by a bath of cold $\mathrm{EtOH} 95 \%$ for $30 \mathrm{~s}$, and finally immersed in chloroform for $1 \mathrm{~min}$. Different sample preparation procedures for MALDI imaging and profiling MS of higher mass proteins were then compared by manually depositing arrays of $0.5 \mu \mathrm{L}$ droplets of matrix solution using a micropipette (profiling) or applying a uniform coating of the matrix solution using an ImagePrep automated sprayer (Bruker Daltonics, Bremen, Germany).

\section{Standard}

Mouse brain tissue sections were washed with chloroform and ethanol and prepared with a matrix solution of $20 \mathrm{mg} / \mathrm{mL} \mathrm{SA}$ in AcN:0.1\% TFA (7:3, vol/vol).

\section{HFIP}

A matrix solution of $20 \mathrm{mg} / \mathrm{mL} \mathrm{SA}$ in pure HFIP was deposited onto the washed tissue, followed by the addition of a recrystallization solution of $20 \mathrm{mg} / \mathrm{mL} \mathrm{SA}$ in AcN: $0.1 \%$ TFA (7:3, vol/vol) [13].

\section{Leinweber}

Mouse brain tissue sections were placed onto a droplet of $20 \mathrm{mg} / \mathrm{mL} \mathrm{SA}$ in $90 \% \mathrm{EtOH}$ containing $0.5 \%$ Triton $\mathrm{X}-100$ and $0.1 \%$ TFA. After the matrix solution was dry, a droplet of a suspension of SA in xylene (freshly prepared by sonication) was deposited onto the tissue and the tissue dried in a vacuum desiccator. Additional droplets of matrix were then added using $20 \mathrm{mg} / \mathrm{mL}$ SA solutions in $90 \% \mathrm{EtOH}$ and in $50 \%$ AcN [12].

\section{Tween}

A matrix solution of $20 \mathrm{mg} / \mathrm{mL} \mathrm{SA}$ in AcN:0.1\% TFA (7:3, vol/vol) and containing a low concentration of Tween 20 was deposited onto the washed tissue and allowed to dry [26].

\section{$\mathrm{H}_{2} \mathrm{O}_{2}$}

A $3 \%$ solution of $\mathrm{H}_{2} \mathrm{O}_{2}$ was deposited onto the tissue and left to incubate for $30 \mathrm{~min}$ in a saturated vapor pressure chamber. The tissue was then dried in a vacuum desiccator and prepared using a matrix solution of $20 \mathrm{mg} / \mathrm{ml} \mathrm{SA}$ in AcN:0.1\% TFA (7:3, vol/vol).

\section{Mass Spectrometry}

All experiments were performed using an AutoFlex III MALDI-TOF (Bruker Daltonics, Bremen, Germany) equipped with an MCP detector and a high mass detector (HM1, CovalX, Switzerland) and were controlled using FlexControl 3.0. All protein spectra were then processed with FlexAnalysis 3.0 using the Top Hat baseline subtraction method and four cycles of Gauss smoothing with a width of $2 \mathrm{~m} / \mathrm{z}$.

MALDI mass analysis of higher mass proteins was found to require higher laser fluence. For these experiments, the laser offset was set to $30 \%$, laser range to $20 \%$, laser power to $70 \%$, and the laser focus to medium. Mass analysis was performed using delayed extraction (800 ns), $20 \mathrm{kV}$ acceleration voltage, and all ions below 
$3.5 \mathrm{kDa}$ were suppressed using an ion deflector. The ion signals from $3.5-100 \mathrm{k} \mathrm{m} / \mathrm{z}$ were recorded using a 0.5 $\mathrm{GHz}$ digitization rate and the mass spectra externally calibrated using insulin clusters and BSA clusters ([nM + $\mathrm{H}]^{+}, n=1-4$ for insulin and $n=1-2$ for BSA).

MALDI imaging MS experiments were performed using a pixel (and laser raster) size of $200 \times 200 \mu \mathrm{m}$, 1000 laser shots for each pixel, and were acquired in fully automated mode using FlexImaging 2.1. Mass analysis of each pixel took $\sim 6 \mathrm{~s}$.

\section{Results and Discussion}

It has previously been shown that washing the tissue sections with organic solvents such as chloroform and $\mathrm{EtOH}$ before matrix deposition increases the number and intensities of protein signals up to $20 \mathrm{kDa}$ [27-29]. To test if the increased high mass sensitivity and charge capacity of the high mass HM1 detector may benefit imaging MS of higher mass proteins, mouse brain tissue sections were washed with chloroform and ethanol, prepared with a matrix solution of $20 \mathrm{mg} / \mathrm{mL} \mathrm{SA}$ in AcN:0.1\% TFA (7:3, vol/vol), and then analyzed using an AutoFlex III MALDI-ToF equipped with an MCP and a HM1 detector. When selected, the HM1 detector is mechanically moved into the ion optical flight path, in front of the MCP detector (18 $\mathrm{cm}$ on the Autoflex III). Once the detector is in position, the post-acceleration voltage $(20 \mathrm{kV})$ and gain voltage $(2 \mathrm{kV})$ are applied and the detector signal switched to the output of the HM1 detector. The whole process takes $\sim 1 \mathrm{~min}$.

Figure 1 shows the spectra obtained by accumulating of 10,000 laser shots over the whole tissue. The MS spectrum recorded with the MCP detector shows many signals up to $\mathrm{m} / \mathrm{z} 20,000$ but only a few very low intensity peaks of higher $\mathrm{m} / \mathrm{z}$ (Figure 1a). In contrast, the mass spectrum obtained with the high mass HM1 detector contains many peaks up to $\mathrm{m} / \mathrm{z} 50,000$ (Figure $1 b)$. Several studies have established that the detection sensitivity of higher mass proteins using an MCP detector is highly attenuated in multi-component mixtures, due to detector saturation [14, 17, 24, 25]. The tissues analyzed in a MALDI imaging and profiling MS analysis contain a very large number of proteins that will exacerbate this loss of sensitivity due to detector saturation.

Images of proteins were obtained from another tissue section, obtained from a different region of a mouse brain, after washing in organic solvents and SA matrix deposition by automatic spraying using both the MCP and the high mass HM1 detectors. The dataset recorded with the high mass HM1 detector included many protein signals above $\mathrm{m} / \mathrm{z} 30,000$ with a mean $\mathrm{S} / \mathrm{N}$ level above 4, Figure 2. Molecular images of the higher mass protein peaks detected at $\mathrm{m} / \mathrm{z} 44,600,46,800$, and 66,000 all generated smooth images with clearly different distributions.

The highest mass MALDI images previously reported show the distributions of a protein detected at
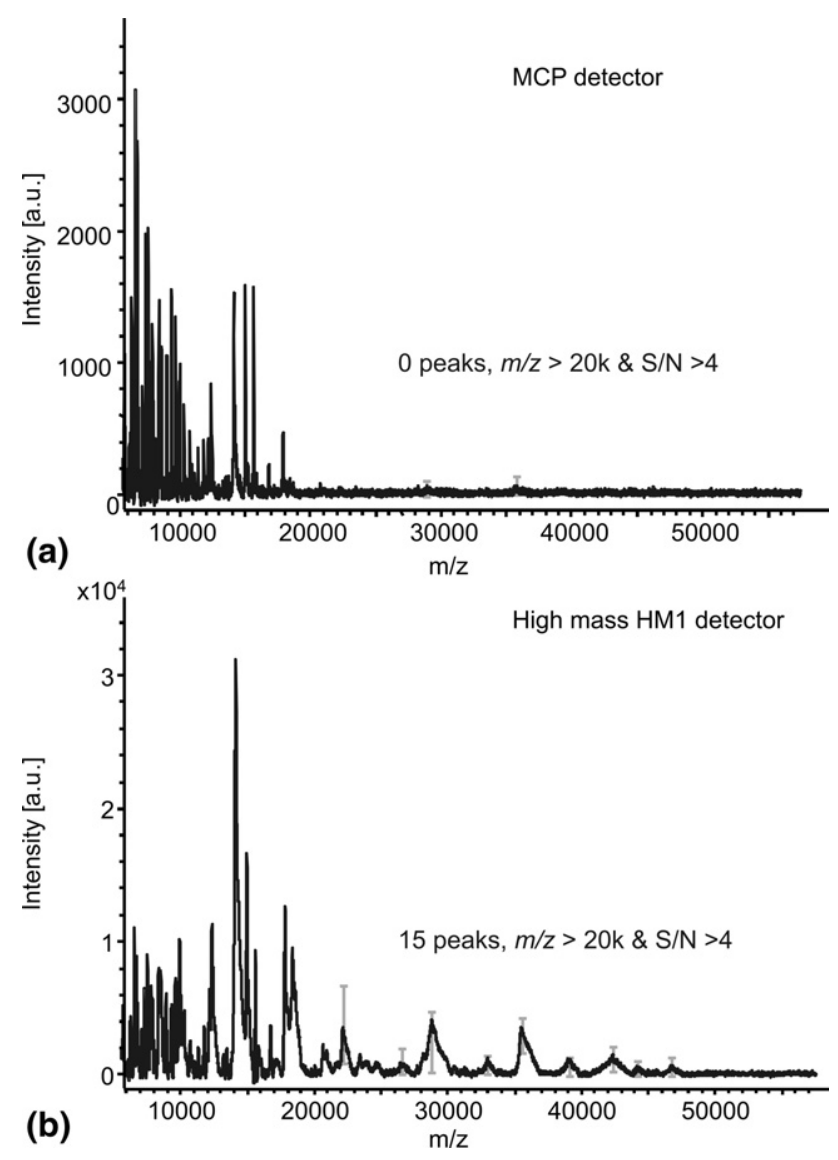

Figure 1. Example MS spectra from a single mouse brain tissue section after deposition of the matrix solution $20 \mathrm{mg} / \mathrm{mL} \mathrm{SA}$ in AcN:0.1\% TFA (7:3, vol/vol) and measured using an MCP detector (a) and the high mass HM1 detector (b). The number of peaks above $20 \mathrm{kDa}$ with $\mathrm{S} / \mathrm{N}>4$ is indicated. The error bars show the variability of the higher mass protein peaks across six repeats. Note that the two detectors have different intensity scales.

$m / z$ 47,900 [12] and at $m / z$ 66,460 [30]. The former publication includes many peaks between 25 and 50 $\mathrm{kDa}$, whereas the latter reports only the protein at 66,460 . In the former report the tissue was prepared using a stepwise sample preparation protocol using Triton X-100 and xylene, which had been developed for the analysis of higher mass proteins, but the experiment was performed using an MCP detector. The results shown above clearly indicate that an MCP detector may under-represent protein ions of higher $\mathrm{m} / \mathrm{z}$.

Several sample preparation strategies have been reported for the analysis of higher mass proteins. A comparison of the mass spectra recorded with an $\mathrm{MCP}$ detector and the high mass HM1 detector for several of these sample preparation strategies explicitly demonstrates the higher sensitivities that can be obtained using the high mass HM1 detector. Figures $3 a$ and $b$ show the mass spectra obtained using the Triton X-100 and xylene protocol developed by Leinweber et al. [12]. The mass spectrum obtained using the $\mathrm{MCP}$ contains weak peaks at higher $\mathrm{m} / \mathrm{z}$ with low $\mathrm{S} / \mathrm{N}$, which are consistent with the mass spectra and pixilated images 


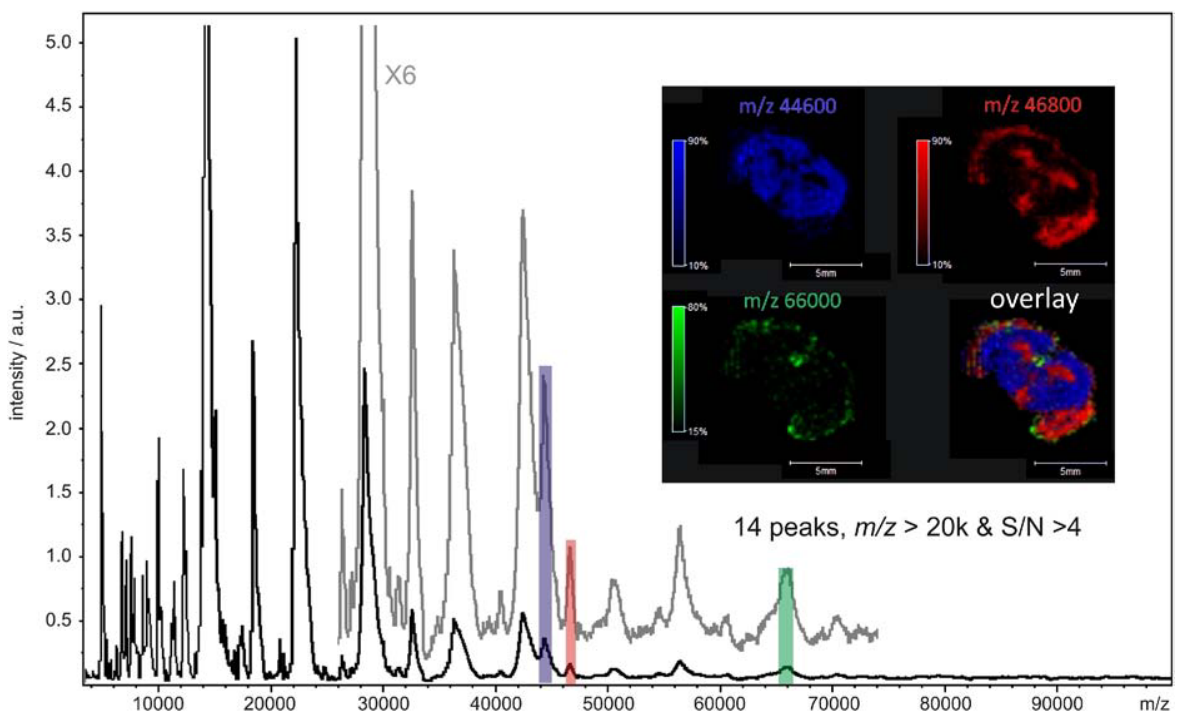

Figure 2. Mean mass spectrum and molecular images of proteins detected at $m / z 44,600,46,800$, and 66,000 from a mouse brain tissue section using the high mass HM1 detector. The tissue was washed with chloroform and ethanol before deposition of the matrix solution $20 \mathrm{mg} / \mathrm{mL} \mathrm{SA}$ in AcN:0.1\% TFA $(7: 3, \mathrm{vol} / \mathrm{vol})$.

included in the original article. When analyzed using the high mass HM1 detector intense peaks up to 50,000 $\mathrm{m} / \mathrm{z}$ and several weaker peaks at even higher mass are obtained. Franck et al. recently reported a multistep sample preparation protocol based on the highly corrosive solvent HFIP [13]. The mass spectra obtained with the MCP can contain weak peaks up to $50,000 \mathrm{~m} / \mathrm{z}$, Figure 3 c tissue 2, but sometimes the peaks are barely discernable, Figure $3 c$ tissue 1 . When analyzed with the high mass HM1 detector, both tissues generated a series of high intensity peaks up to $60,000 \mathrm{~m} / \mathrm{z}$. On occasion, the combination of the HFIP sample treatment and a high mass HM1 detector even led to the detection of peaks exceeding 100,000 m/z (supplementary Figure 1, which can be found in the electronic version of this article).

Figures 1, 2, and 3 demonstrate the increased sensitivity provided by the high mass HM1 detector and also indicate that low detection efficiency of higher mass proteins is one of the principal causes for their absence in previous MALDI imaging MS studies. Further support for this assertion was obtained by testing newly reported sample preparation strategies: Mainini et al. recently demonstrated that the addition of a small amount of chaotropic agents or detergents $(0.05 \%$ SDS, PPS, or Triton X-100) to the matrix solution improved the intensity and number of protein peaks in the mass spectrum [26]. These experiments were performed using an MCP detector, and the majority of the protein peaks were detected at less than $25,000 \mathrm{~m} / z$. The increased sensitivity for high mass proteins provided by the HM1 detector revealed that chaotropes and detergents could also aid in the detection of higher mass proteins. Figure 4a shows how the intensity of the peaks between 40,000 and 50,000 m/z increases with increasing
Tween content. An imaging analysis of two adjacent tissue sections, only one of which was prepared with Tween, clearly demonstrates that the higher mass proteins were only obtained from the tissue prepared with Tween (Figure 4a).

We then tested whether any of the steps from immunohistochemical protocols could be adapted for MALDI imaging and profiling MS, to improve the extraction and thus detection of higher mass proteins. Remarkably, it was found that the use of a commercially available peroxidase blocking solution containing 3\% $\mathrm{H}_{2} \mathrm{O}_{2}$ also enhanced the detection of higher mass proteins. Figure $4 \mathrm{~b}$ shows examples of profiles obtained from adjacent tissue sections prepared by first treating the tissue with a $3 \% \mathrm{H}_{2} \mathrm{O}_{2}$ solution and then depositing the standard $20 \mathrm{mg} / \mathrm{mL}$ sinapinic acid matrix solution. As can be seen, a series of intense protein peaks were obtained up to $50 \mathrm{kDa}$, as well as some weaker peaks of even higher mass. The application of $\mathrm{H}_{2} \mathrm{O}_{2}$ has been shown to oxidize cysteine and methionine residues [31] and to lead to the partial denaturation of proteins [32]. As occurs with chaotropes such as SDS, we speculate that $\mathrm{H}_{2} \mathrm{O}_{2}$ aided denaturation of proteins might increase their solubilization in the matrix solution.

Closer inspection of the spectra obtained with the MCP and HM1 detectors, Figures 1 and 3, revealed that several of the higher mass peaks observed with the HM1 detector were sometimes also observed with the MCP but were detected with much lower intensity. This is consistent with the higher detection efficiency of higher mass ions using the HM1 detector: the profiling mass spectra are the result of $10 \mathrm{k}$ accumulated singlelaser-shot mass spectra, the HM1 detector ensures a larger fraction of the higher mass ions contribute to the final accumulated spectrum. Nevertheless, the underly- 


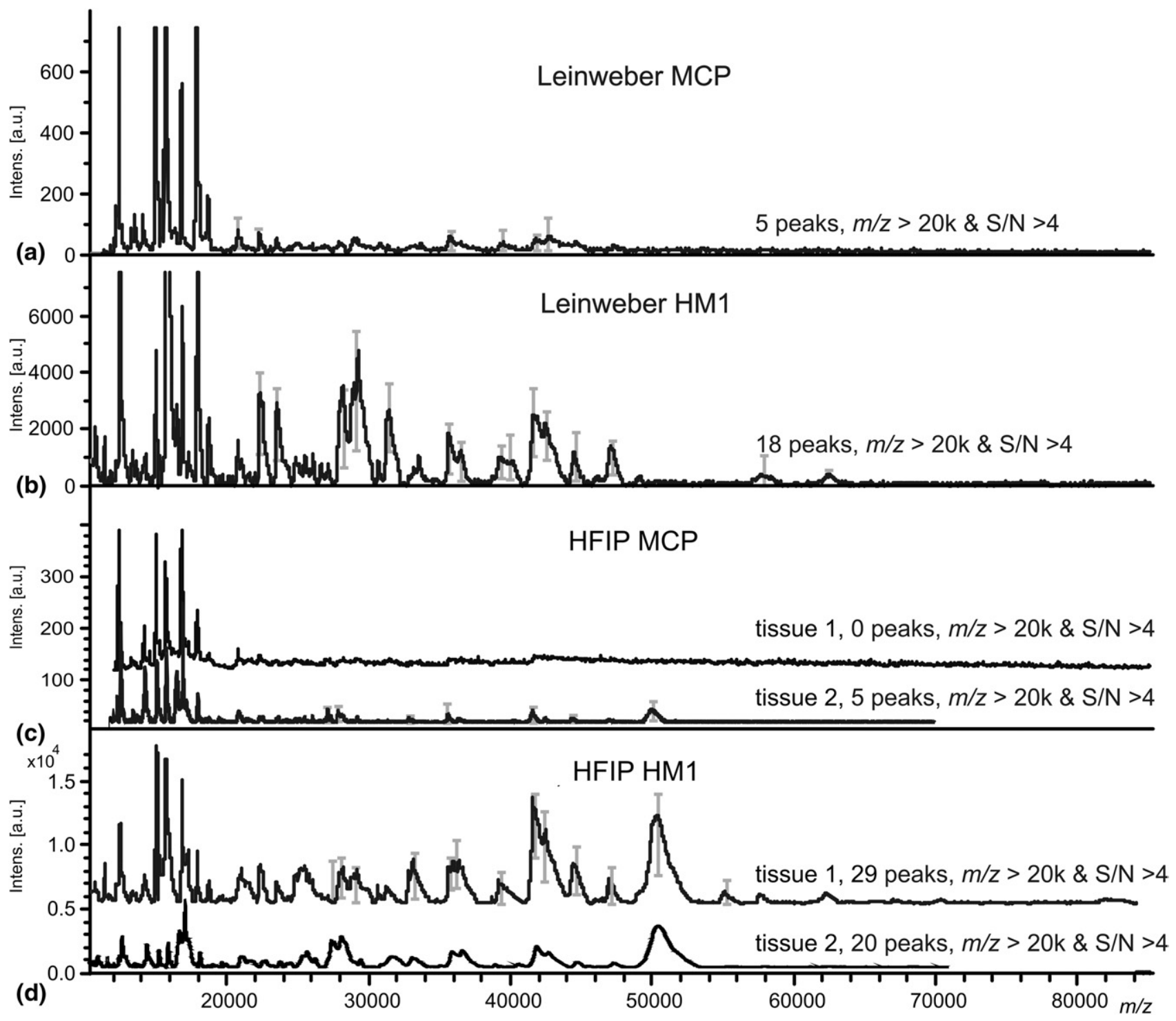

Figure 3. Comparison of spectra obtained from previously published sample preparation protocols for higher mass proteins using an MCP and a high mass HM1 detector. Leinweber [12] protocol using an MCP (a) and the HM1 detector (b). HFIP protocol [13] using an MCP (c) and the HM1 detector (d). The number of peaks above $20 \mathrm{kDa}$ with a $\mathrm{S} / \mathrm{N}>4$ is indicated. The error bars show the variability of the higher mass protein peaks across six measurement repeats. Note that the two detectors have different intensity scales.

ing spectrum, the ions produced by the experiment, remains identical. For MALDI imaging MS experiments, in which each pixel is analyzed with fewer laser shots, the increased sensitivity offered by the high mass HM1 detector for higher mass proteins ensures that more pixels contribute signal to the final image (Figure 2).

The above results demonstrate that a range of different sample preparation strategies enable higher mass proteins to be analyzed provided they are detected with sufficient efficiency. However, the mass resolution of the peaks in the spectra measured with the high mass HM1 detector are lower than those measured using the MCP detector, and is a consequence of the postacceleration of the secondary ions after the conversion dynode (which provides the high mass sensitivity). The low mass resolution of the high mass HM1 detector reduces its suitability for MALDI imaging and profiling MS because too many protein signals overlap. Nevertheless, it clearly demonstrates that the lack of detection of higher mass protein ions is partly due to the low detection efficiency of higher mass protein ions using MCPs, a phenomenon which is exacerbated by the significant chemical background. The HM1 detector has been designed for the detection of very large protein ions and protein complexes, including masses exceeding $10^{6} \mathrm{Da}$. For very large molecules, i.e., several hundred $\mathrm{kDa}$ and greater, the detected peak width is limited by the isotopic distribution and adduct formation [33] and not by the response time of the detector. For the mass range accessible by MALDI imaging and 


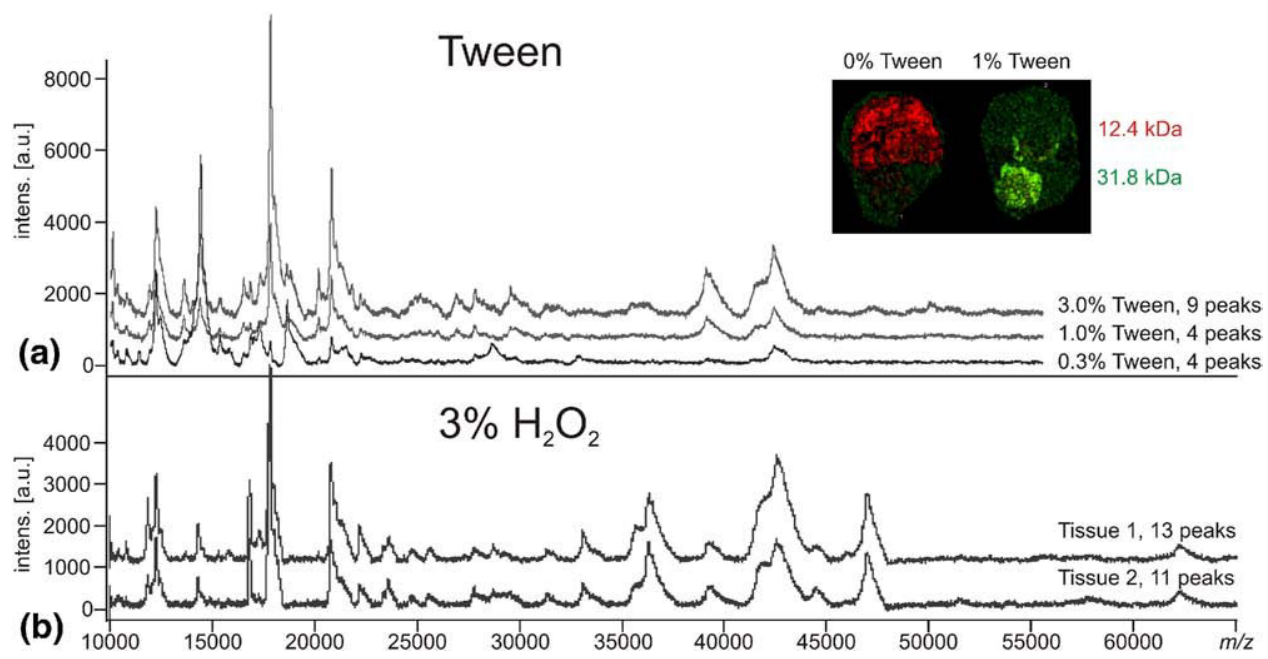

Figure 4. (a) Addition of the detergent Tween 20 to the matrix solution $20 \mathrm{mg} / \mathrm{mL}$ SA in AcN:0.1\% TFA $(7: 3, \mathrm{vol} / \mathrm{vol})$ leads to the detection of more high mass protein ions. (b) Pretreatment of the tissue with a $3 \% \mathrm{H}_{2} \mathrm{O}_{2}$ solution before the deposition of the matrix solution $20 \mathrm{mg} / \mathrm{mL} \mathrm{SA}$ in AcN:0.1\% TFA $(7: 3, \mathrm{vol} / \mathrm{vol})$ leads to the detection of higher mass proteins. The number of peaks above $20 \mathrm{kDa}$ with a $\mathrm{S} / \mathrm{N}>4$ is indicated.

profiling MS, below $\sim 150 \mathrm{kDa}$, it would be beneficial to decrease the response time of the high mass HM1 detector (350 ns), or CovalX's revised HM2 detector (250 ns), to $\sim 10$ ns while maintaining improved sensitivity and lack of saturation.

\section{Conclusion}

Tissue analysis using MALDI imaging and profiling MS experiments can generate rich spectra containing many peptides and proteins. However, the number of lower mass proteins, $<25 \mathrm{kDa}$, far exceeds those of higher mass. The results shown here clearly demonstrate that many existing sample preparation protocols generate higher mass protein ions but the ions are detected with low efficiency using the standard MCP detector. The increased signal intensities of higher mass proteins obtained with the high mass HM1 detector, relative to an MCP, are consistent with the latter's known loss of detection sensitivity with increasing mass and ion load [14]. MALDI imaging and profiling MS generates a significant chemical background [18], which will exacerbate any losses of sensitivity due to saturation. The increased detection sensitivity and, particularly, the lack of detector saturation provided by the HM1 detector, enables the acquisition of spectra containing proteins up to $\sim 70 \mathrm{kDa}$ as well as the detection of even higher mass proteins. These results, the first reporting the utility of such detectors for MALDI imaging and profiling MS, demonstrate that the sensitive analysis of higher mass proteins directly from tissue requires a detector technology that can withstand the high chemical background and detect higher mass proteins with higher efficiency.

\section{Acknowledgments}

The authors acknowledge funding for this work by the ZonMw Horizon program Multiplex Imaging of Tissue Arrays, project number 93519026 (L.McD.), and by grants from the Centre National de la Recherche Scientifique (CNRS) Direction de la Politique Industrielle et Institut des Sciences de la Vie (to M.S. and I.F.), Ministère de L'Education Nationale, de L'Enseignement Supérieur et de la Recherche, Agence Nationale de la Recherche (ANR PCV to I.F.), Institut du Cancer (INCA to I.F.).

\section{Appendix A Supplementary Material}

Supplementary material associated with this article may be found in the online version at doi:10.1016/ j.jasms.2010.07.011.

\section{References}

1. McDonnell, L. A.; Corthals, G. L.; Willems, S. M.; van Remoortere, A. van Zeijl, R. J. M.; Deelder, A. M. Peptide and Protein Imaging Mass Spectrometry in Cancer Research. J. Proteom. 2010, epub ahead of print.

2. McDonnell, L. A.; Heeren, R. M. A. Imaging Mass Spectrometry. Mass Spectrom. Rev. 2007, 26, 606-643.

3. Chaurand, P.; Latham, J. C.; Lane, K. B.; Mobley, J. A.; Polosukhin, V. V.; Wirth, P. S.; Nanney, L. B.; Caprioli, R. M. Imaging Mass Spectrometry of Intact Proteins from Alcohol-Preserved Tissue Specimens: Bypassing Formalin Fixation. J. Proteome Res. 2008, 7, 3543-3555.

4. Cornett, D. S.; Reyzer, M. L.; Chaurand, P.; Caprioli, R. M. MALDI Imaging Mass Spectrometry: Molecular Snapshots of Biochemical Systems. Nat. Methods 2007, 4, 828-833.

5. Franck, J.; Arafah, K.; Elayed, M.; Bonnel, D.; Vergara, D.; Jacquet, A.; Vinatier, D.; Wisztorski, M.; Day, R.; Fournier, I.; Salzet, M. MALDI Imaging Mass Spectrometry: State of the Art Technology in Clinical Proteomics. Mol. Cell. Proteom. 2009, 8, 2023-2033.

6. Seeley, E. H.; Caprioli, R. M. Molecular Imaging of Proteins in Tissues by Mass Spectrometry. Proc. Natl. Acad. Sci. U.S.A. 2008, 105, 1812618131.

7. Stoeckli, M.; Staab, D.; Schweitzer, A. Compound and Metabolite Distribution Measured by MALDI Mass Spectrometric Imaging in Whole-Body Tissue Sections. Int. J. Mass Spectrom. 2007, 260, 195-202.

8. Burnum, K. E.; Cornett, D. S.; Puolitaival, S. M.; Milne, S. B.; Myers, D. S.; Tranguch, S.; Brown, H. A.; Dey, S. K.; Caprioli, R. M. Spatial and Temporal Alterations of Phospholipids Determined by Mass Spectrom- 
etry During Mouse Embryo Implantation. J. Lipid Res. 2009, 50, $2290-2298$

9. Djidja, M. C.; Claude, E.; Snel, M. F.; Scriven, P.; Francese, S.; Carolan, V.; Clench, M. R. MALDI-Ion Mobility Separation-Mass Spectrometry Imaging of Glucose-Regulated Protein $78 \mathrm{kDa}$ (Grp78) in Human Formalin-Fixed, Paraffin-Embedded Pancreatic Adenocarcinoma Tissue Sections. J. Proteome Res. 2009, 8, 4876-4884.

10. Scholz, B.; Sköld, K.; Kultima, K.; Fernandez, C.; Waldemarson, S.; Savitski, M.; Svensson, M.; Borén, M.; Andrén, P.; Zubarev, R.; James, P. Impact of Temperature-Dependent Sampling Procedures in Proteomics and Peptidomics - a Characterization of the Liver and Pancreas PostMortem Degradome. Mol. Cell. Proteom. 2010, in press.

11. Grey, A. C.; Chaurand, P.; Caprioli, R. M.; Schey, K. L. MALDI Imaging Mass Spectrometry of Integral Membrane Proteins from Ocular Lens and Retinal Tissue. J. Proteom. Res. 2009, 8, 3278-3283.

12. Leinweber, B. D.; Tsaprailis, G.; Monks, T. J.; Lau, S. S. Improved MALDI-TOF Imaging Yields Increased Protein Signals at High Molecular Mass. J. Am. Soc. Mass Spectrom. 2009, 20, 89-95.

13. Franck, J.; Longuespée, R.; Wisztorski, M.; Remoortere, A. V.; Zeijl, R. V.; Deelder, A.; Salzet, M.; McDonnell, L.; Fournier I. MALDI Mass Spectrometry Imaging of Proteins Exceeding 30,000 Dalton. Med. Sci. Monit. 2010, 16, epub ahead of print.

14. Chen, X.; Westphall, M. S.; Smith, L. M. Mass Spectrometric Analysis of DNA Mixtures: Instrumental Effects Responsible for Decreased Sensitivity with Increasing Mass. Anal. Chem. 2003, 75, 5944-5952.

15. Gilmore, I. S.; Seah, M. P. Ion detection Efficiency in SIMS: Dependencies on Energy, Mass, and Composition for Microchannel Plates Used in Mass Spectrometry. Int. J. Mass Spectrom. 2000, 202, 217-229.

16. Coeck, S.; Beck, M.; Golovko, B.; Delauré, V. V.; Herbane, M.; Lindroth, A.; Kopecky, S.; Kozlov, V. Y.; Kraev, I. S.; Phalet, T.; Severijns, N. Microchannel Plate Response to High-Intensity Ion Bunches. Nucl. Instrum. Methods A 2006, 557, 516-522.

17. Westman, A.; Brinkmalm, G.; Barofsky, D. F. MALDI Induced Saturation Effects in Chevron Microchannel Plate Detectors. Int. J. Mass Spectrom. Ion Processes 1997, 169/170, 79-87.

18. McDonnell, L. A.; van Remoortere, A.; van Zeijl, R. J. M.; Deelder, A. M. Mass Spectrometry Image Correlation: Quantifying Colocalization. I. Proteome Res. 2008, 7, 3619-3627.

19. Norris, J. L.; Cornett, D. S.; Mobley, J. A.; Andersson, M.; Seeley, E. H.; Chaurand, P.; Caprioli, R. M. Processing MALDI Mass Spectra to Improve Mass Spectral Direct Tissue Analysis. Int. I Mass Spectrom. 2007, 260, 212-221.

20. Spengler, B.; Kirsch, D.; Kaufmann, R.; Karas, M.; Hillenkamp, F.; Giessmann, U. The Detection of Large Molecules in Matrix-Assisted UV-Laser Desorption. Rapid Commun. Mass Spectrom. 1990, 4, 301-305.
21. Berkenkamp, S.; Kirpekar, F.; Hillenkamp, F. Infrared MALDI Mass Spectrometry of Large Nucleic Acids. Science 1998, 281, 260-262.

22. Berkenkamp, S.; Menzel, C.; Karas, M.; Hillenkamp, F. Performance of Infrared Matrix-assisted Laser Desorption/Ionization Mass Spectrometry with Lasers Emitting in the 3 ím Wavelength Range. Rapid Commun. Mass Spectrom. 1997, 11, 1399-1406.

23. Wenzel, R. J.; Matter, U.; Schultheis, L.; Zenobi, R. Analysis of Megadalton Ions Using Cryodetection MALDI Time-of-Flight Mass Spectrometry. Anal. Chem. 2005, 77, 4329-4337.

24. Yanes, O.; Avilés, F. X.; Wenzel, R.; Nazabal, A.; Zenobi, R.; Calvete, J. J Proteomic Profiling of a Snake Venom Using High Mass Detection MALDI-TOF Mass Spectrometry. J. Am. Soc. Mass Spectrom. 2007, 18 600-606.

25. Wenzel, R. J.; Kern, S.; Zenobi, R. Proceedings of the 54th ASMS Conference on Mass Spectrometry and Allied Topics; Seattle, WA, May, 2006.

26. Mainini, V.; Angel, P.; Caprioli, R. M. Proceedings of the 58th ASMS Conference on Mass Spectrometry and Allied Topics; Salt Lake City, UT, May, 2010.

27. Lemaire, R.; Wisztorski, M.; Desmons, A.; Tabet, J. C.; Day, R.; Salzet, M.; Fournier, I. MALDI-MS Direct Tissue Analysis of Proteins: Improving Signal Sensitivity Using Organic Treatments. Anal. Chem. 2006, 78 7145-7153.

28. Schwartz, S. A.; Reyzer, M. L.; Caprioli, R. M. Direct Tissue Analysis Using Matrix-Assisted Laser Desorption/Ionization Mass Spectrometry: Practical Aspects of Sample Preparation. J. Mass Spectrom. 2003, 38, 699-708.

29. Seeley, E. H.; Oppenheimer, S. R.; Mi, D.; Chaurand, P.; Caprioli, R. M. Enhancement of Protein Sensitivity for MALDI Imaging Mass Spectrometry After Chemical Treatment of Tissue Sections. J. Am. Soc. Mass Spectrom. 2008, 19, 1069-1077.

30. Mangé, A.; Chaurand, P.; Perrochia, H.; Roger, P.; Caprioli, R. M.; Solassol J. Liquid Chromatography-Tandem and MALDI Imaging Mass Spectrometry Analyses of RCL2/CS100-Fixed, Paraffin-Embedded Tissues: Proteomics Evaluation of an Alternate Fixative for Biomarker Discovery. J. Proteome Res. 2009, 8, 5619-5628.

31. Milzani, A.; Rossi, R.; Simplicio, P. D.; Giustarini, D.; Colombo, R DalleDonne, I. The Oxidation Produced by Hydrogen Peroxide on Ca-ATP-G-Actin. Protein Sci. 2000, 9, 1774-1782.

32. Kim, Y. H.; Berry, A. H.; Spencer, D. S.; Stites, W. E. Comparing the Effect on Protein Stability of Methionine Oxidation Versus mutagenesis: steps toward engineering oxidative resistance in proteins. Protein Eng. 2001, 14, 343-347.

33. Bahr, U.; Stahl-Zeng, J.; Gleitsmann, E.; Karas, M. Delayed Extraction Time-of-flight MALDI Mass Spectrometry of Proteins above 25,000 Da. J. Mass Spectrom. 1997, 32, 1111-1116. 